\title{
Cancer predisposing $B A R D 1$ mutations affect exon skipping and are associated with overexpression of specific $B A R D 1$ isoforms
}

\author{
MAGDALENA RATAJSKA $^{1,7^{*}}$, MAGDALENA MATUSIAK $^{1 *}$, ALINA KUZNIACKA $^{1}$, BARTOSZ WASAG $^{1}$, \\ IZABELA BROZEK $^{1,2}$, WOJCIECH BIERNAT ${ }^{3}$, MAGDALENA KOCZKOWSKA ${ }^{1}$, JAROSLAW DEBNIAK ${ }^{4}$, \\ MARCIN SNIADECKI $^{4}$, PIOTR KOZLOWSKI ${ }^{5}$, KATARZYNA KLONOWSKA ${ }^{5}$, MAXIM PILYUGIN ${ }^{6}$, \\ DARIUSZ WYDRA $^{4}$, GEOFF LAURENT ${ }^{7,8}$, JANUSZ LIMON ${ }^{1,2}$ and IRMGARD IRMINGER-FINGER ${ }^{6,7}$
}

${ }^{1}$ Department of Biology and Genetics, Medical University of Gdansk, 80-211 Gdansk; ${ }^{2}$ Regional Oncological Outpatient Clinic, 80-219 Gdansk; ${ }^{3}$ Department of Pathology, Medical University of Gdansk, 80-214 Gdansk; ${ }^{4}$ Department of Gynecology, Medical University of Gdansk, 80-402 Gdansk; ${ }^{5}$ European Centre of Bioinformatics and Genomics, Institute of Bioorganic Chemistry, Polish Academy of Sciences, 61-138 Poznan, Poland; ${ }^{6}$ Laboratory of Molecular Gynecology and

Obstetrics, University Hospital Geneva-Belle-Idée, 2, Chemin du Petit Bel Air, Chêne Bourg CH-1225, Switzerland;

${ }^{7}$ Centre for Cell Therapy and Regenerative Medicine and ${ }^{8}$ Lung Institute of Western Australia,

School of Medicine and Pharmacology, University of Western Australia, Harry Perkins Institute of Medical Research, M519, QEII Medical Centre, Nedlands WA 6009, Australia

Received May 27, 2015; Accepted July 2, 2015

DOI: $10.3892 /$ or.2015.4235

\begin{abstract}
BARD1 is the main binding partner of BRCA1 and is required for its stability and tumor-suppressor functions. In breast cancer and other epithelial cell carcinomas, alternatively spliced isoforms of BARD1 are highly upregulated and correlated with poor outcome. Recent data indicate that germline mutations of $B A R D 1$ may predispose to breast and/or ovarian cancer. To evaluate the role of $B A R D I$ germline mutations in predisposition to ovarian cancer we scanned a cohort of 255 patients for the presence of previously reported mutations located in exons 5, 8 and 10 using high-resolution melting analysis. Within this group we identified single-patients carrying mutation in exon 8 (c.1690C $>\mathrm{T}$, p.Gln564Ter), two different variants in exon 10 (c.1972C $>$ T, p.Arg658Tyr; c.1977A $>$ G, p.=) and a carrier of novel missense mutation located in exon 5 (c.1361C $>$ T, p.Pro454Leu). Three out of four identified mutations alter exonic splicing enhancing motives and result in expression of incorrect splicing skipping of exons 5, 8, and 2-9, respectively. Our data indicate that $B A R D 1$ variants may predispose to ovarian cancer in limited number of patients although based on actual data it is difficult to estimate its actual penetrance.
\end{abstract}

Correspondence to: Dr Magdalena Ratajska, Department of Biology and Genetics, Medical University of Gdansk, Debinki 1, 80-211 Gdansk, Poland

E-mail: mratajska@gumed.edu.pl; magda.ratajska@uwa.edu.au

${ }^{*}$ Contributed equally

Key words: BARD1, ovarian cancer, mutations, splicing

\section{Introduction}

Ovarian cancer is a heterogeneous group of tumors, where epithelial ovarian cancer accounts for the majority of cases. The 5-year survival for invasive ovarian cancer strongly depends on the stage at time of diagnosis and varies from 30 to $90 \%(1,2)$. In the majority of patients late diagnosis and high morbidity result mainly from asymptomatic manifestation of the disease (3). Although multiple genetic and epigenetic changes have been studied, and some are characteristic for ovarian cancer, it is still not clear how these changes affect tumorigenesis. To date at least 15 oncogenes and 16 potential tumor-suppressor genes in several signaling pathways have been associated with ovarian cancer (4).

In the majority of populations, $\sim 5-15 \%$ of all ovarian cancer cases are caused by inheritance of mutations in genes with an autosomal dominant pattern of transmission (such as $B R C A 1 / 2$ ). Although the actual proportion strongly depends on the studied population and may be much higher, reaching $30 \%$ in the Ashkenazi Jews (5-8). In Poland, the portion of hereditary ovarian cancer due to $B R C A 1 / 2$ mutation ranges from 13.5 to $14.9 \%$ (9-11).

Another $\sim 6 \%$ of constitutive ovarian cancer cases are related to alterations in low and moderate-penetrant genes (12). These genes, products of which are known to interact with BRCA1/2, are involved in DNA repair and cell cycle regulation and therefore are good candidates for possible breast and ovarian susceptibility genes $(13,14)$.

The human BARDl gene (BRCA1-associated RING domain 1) is located at the long arm of chromosome 2 (2q34-35) and encodes a nuclear protein of 777 amino acids that shares many structural and functional similarities with BRCA1 (15-17). Like BRCA1, BARD1 has an amino-terminal RING-finger motif and two carboxy-terminal BRCT 
domains (15). The RING-finger motif is known to be essential for BRCA1/BARD1 heterodimer formation, while BRCT domains are found in proteins maintaining genome integrity (18). Proper interaction between these proteins is crucial for BRCA1 stability and E3 ubiquitin ligase activity of the BRCA1/BARD1 complex $(16,17,19)$.

BARD1 has additionally three ankyrin (ANK) repeats potentially mediating protein-protein interactions and present in many proteins of various functions $(20,21)$. Interestingly, no other proteins comprising RING, ANK and BRCT motifs together are known (16).

Like BRCA1, BARD1 shows highest expression in actively proliferating cells and those that undergo apoptosis $(17,22)$. Loss of BARD1, as well as BRCA1, leads to developmental retardation and early embryonic lethality of corresponding knockout mice; cells from these mice are characterized by chromosomal instability (23). In addition, it was observed that tumors with homozygous deletions of the entire BARDl gene displayed a BRCA1 mutation-like expression profile (24).

Germline mutations in the BARDl gene, although detected with low frequency and in a limited number of patients, can be qualified as novel candidates for ovarian cancer susceptibility in a subset of families negative for BRCA1/2 mutations. The first study linking $B A R D 1$ with ovarian cancer presented a patient with clear cell ovarian carcinoma in who the missense c. $1692 \mathrm{G}>\mathrm{C}$ (p.Gln564His) mutation was identified (25). The p.Gln564His reduces binding of BARD1 to the polyadenylation cleavage specification complex (CstF-50) and abrogates p53-dependent apoptosis $(22,26)$. Most recent publications reported three BARD1 mutations: One affecting splicing, c.1977A $>\mathrm{G}, \mathrm{p} .=$, one non-sense, p.Gln715Ter and one frameshift c.2148delCA; p.Thr716fs*12 (12,27,28). Finally, germline BARD1 mutations were identified in patients with a breast cancer $(24,27,29-31)$, cervical cancer (32), and neuroblastoma (33).

In the present study, we present four different possibly pathogenic $B A R D 1$ variants identified in a group of unselected ovarian cancer patients. Three of the identified alterations result in incorrect splicing of the corresponding exons, which may prompt expression of specific BARD1 isoforms and promote carcinogenesis.

\section{Materials and methods}

Study population. The study comprised 255 unselected ovarian cancer patients referred to the Department of Gynaecological Oncology of Medical University of Gdansk between 1995 and 2009. Within the study group $162(63.5 \%)$ patients were diagnosed with serous ovarian cancer. The remaining $36.5 \%$ of tumors were classified as endometroid $(n=30 / 255 ; 12 \%)$; mucinous $(n=25 / 255 ; 10 \%)$; clear cell $(n=17 / 255 ; 7 \%)$; and non-differentiated $(n=17 / 255 ; 7 \%)$. Four tumors $(n=4 / 255 ; 1 \%)$ did not have complete histopatological classification. Average age at diagnosis was 58 (range, 20-88 years). Informed consent was obtained from all of the patients and the study was approved by the Medical Review Board of Medical University of Gdansk (NKEB/399/2011-2012). The frequency of identified BARDI variants was investigated in an unselected population-based control group of 1,000 anonymous samples collected at birth (dried blood spots) and in a group of 200 healthy females matched by age.
Blood samples. Patient samples: Genomic DNA was extracted from the whole blood using the Genomic Midi AX kit (A\&A Biotechnology, Poland).

In addition, from selected patients a blood sample was collected into Tempus ${ }^{\mathrm{TM}}$ Blood RNA Tubes and total RNA was isolated with Tempus ${ }^{\mathrm{TM}}$ Spin RNA Isolation kit (Life Technologies, USA). cDNA was synthesized using the Go Script $^{\mathrm{TM}}$ Reverse Transcriptase according to manufacturer's instructions (Promega, USA).

Population-based control group: Genomic DNA was extracted from 1,000 dried blood spots using Kapa Express Extract kit (Kapa Biosystems, USA).

Tissue samples. Ovarian cancer: DNA from ovarian tumors was extracted from formalin-fixed, paraffin-embedded (FFPE) tissue blocks using Kapa Express Extract kit (Kapa Biosystems). Total RNA from FFPE tissue blocks was isolated using the High Pure FFPE RNA Micro kit (Roche Diagnostics, Switzerland).

Chronic myeloid leukemia (CML) controls: In order to verify a presence of identified BARD1 isoforms in a hormone-independent cancer, we examined cDNA from bone marrow cells from $120 \mathrm{CML}$ patients.

Mutation screening. All samples were tested for the presence of three previously described $B A R D 1$ mutations (c.1315-2A $>\mathrm{G}$ in intron 4 ; c.1690C $>\mathrm{T}$ in exon 8 and c.1977A $>\mathrm{G}$ in exon 10) by using high-resolution melting analysis (LightScanner ${ }^{\circledR}$ System; BioFire Defense, USA). Primers listed in Table I were designed based on the $B A R D 1$ gene sequence obtained for the Ensemble database (http://www.ensembl.org; BARD1: ENSG00000138376). In order to simplify subsequent sequencing analysis, M13 adaptor sequences (indicated by capital letters) were added to the 5'-end of each primer. All amplicons demonstrating melting profiles distinct from those of the wild-type samples were subsequently sequenced (ABI PRISM 3130; Life Technologies). More detailed information on screening protocols, can be obtained from the corresponding author upon request.

Bioinformatics analysis and sequence variation nomenclature. $B A R D 1$ mutations were numbered according to the Human Genome Variation Society guidelines (34). The BARDI sequence was in accordance with GenBank NM_000465.2 All mutations were analyzed for potential pathogenic effect using the following in silico software: Alamut Mutation Interpretation software, ESE finder, Human Splicing Finder, MutPred Splice, Mutation Tester, PolyPhen 2, Rescue ESE and SIFT.

\section{Results}

Here we investigated a role of $B A R D 1$ germline mutations in predisposition to ovarian cancer. Frequency of $B A R D 1$ recurrent mutations was estimated in a group of 255 unselected ovarian cancer patients. Exons 5, 8 and 10 together with flanking intron sequences were analyzed by HRM technique followed by bi-directional sequencing. A summary of the identified $B A R D 1$ alterations is presented in Table II.

BARD1 germline mutations. In patient \#109, diagnosed with advanced serous ovarian cancer at the age of 70 , a novel 
Table I. Sequences of the primers used for amplification of exons 5, 8 and 10 together with PCR and HRM conditions.

\begin{tabular}{|c|c|c|c|c|c|}
\hline No. & Primer name & Primer sequence & $\begin{array}{c}\text { PCR annealing } \\
\text { temperature } \\
\left({ }^{\circ} \mathrm{C}\right)\end{array}$ & $\begin{array}{l}\text { Product length } \\
\text { (bp) }\end{array}$ & $\begin{array}{l}\text { HRM melting } \\
\text { range } \\
\left({ }^{\circ} \mathrm{C}\right)\end{array}$ \\
\hline 1 & BARD1_ex5Frw & TGTAAAACGACGGCCAGTttttcetttetttccttaatgctt & 64 & 236 & $78-88$ \\
\hline 2 & BARD1_ex5Rev & CAGGAAACAGCTATGACCaagagtatatgtggcagaggatga & & & \\
\hline 3 & BARD1_ex8Frw & TGTAAAACGACGGCCAGTtcgtctaatgtttttaacactggt & 68 & 210 & $80-90$ \\
\hline 4 & BARD1_ex8Rev & CAGGAAACAGCTATGACCtctaccccacctcccaaaat & & & \\
\hline 5 & BARD1_ex10Frw & TGTAAAACGACGGCCAGTtcgtctaatgtttttaacactggt & 63 & 293 & $80-90$ \\
\hline 6 & BARD1_ex10Rev & CAGGAAACAGCTATGACCagctgttgaaagggcagaag & & & \\
\hline
\end{tabular}

BARD1, BRCA1-associated RING domain 1.

Table II. BARD1 gene variants identified in intron and exon sequences in 255 patients with ovarian cancer.

\begin{tabular}{|c|c|c|c|c|c|c|c|c|c|c|}
\hline \multirow[b]{2}{*}{ No. } & \multirow[b]{2}{*}{ Intron/exon } & \multirow[b]{2}{*}{ Nucleotide change } & \multirow[b]{2}{*}{ Effect } & \multirow[b]{2}{*}{ Status } & \multicolumn{2}{|c|}{$\begin{array}{l}\text { Patients } \\
(\mathrm{n}=255)\end{array}$} & \multicolumn{2}{|c|}{$\begin{array}{l}\text { Unselected } \\
\text { controls } \\
(\mathrm{n}=1,000)\end{array}$} & \multicolumn{2}{|c|}{$\begin{array}{l}\text { Healthy } \\
\text { controls } \\
(n=200)\end{array}$} \\
\hline & & & & & $\mathrm{n}$ & $\%$ & $\mathrm{n}$ & $\%$ & $\mathrm{n}$ & $\%$ \\
\hline \multicolumn{11}{|c|}{ Sequence variants identified in intron sequences } \\
\hline 1 & 4 & c. $1315-19 A>G$ & $\mathrm{NE}$ & rs6704780 & 130 & 51 & NA & NA & NA & NA \\
\hline 2 & 10 & c. $2001+66 \mathrm{~A}>\mathrm{G}$ & $\mathrm{NE}$ & De Brakeleer et al (29) & 7 & 2.75 & NA & NA & NA & NA \\
\hline \multicolumn{11}{|c|}{ Sequence variants identified in exon sequences } \\
\hline 1 & 5 & $\begin{array}{l}\text { c.1361C }>\text { T } \\
\text { r.[=,1315_1395del] } \\
\text { p.Gly439_Leu465del }\end{array}$ & p.Pro454Leu & Novel & 1 & 0.39 & 0 & 0 & 0 & 0 \\
\hline 2 & 8 & $\begin{array}{l}\text { c.1690C }>\text { T } \\
\text { r.[=,1678_1810del] } \\
\text { p.Met560Ter }\end{array}$ & p.Gln564Ter & Ratajska et al (27) & 1 & 0.39 & 0 & 0 & 0 & 0 \\
\hline 3 & 10 & c. $1972 \mathrm{C}>\mathrm{T}$ & p.Arg658Cys & rs 3738888 & 1 & 0.39 & 3 & 0.3 & 2 & 1 \\
\hline 4 & & $\begin{array}{l}\text { c.1977A }>\mathrm{G} \\
\text { r.[=, 159_1903del] } \\
\text { p.Cys53_Trp635delinsfs*12 }\end{array}$ & $\mathrm{p} .=$ & Ratajska et al (27) & 1 & 0.39 & 1 & 0.1 & 2 & 1 \\
\hline
\end{tabular}

BARD1, BRCA1-associated RING domain 1.

substitution c.1361C $>\mathrm{T}$ located in exon 5 was identified. The substitution results in a change of a highly conserved amino acid (p.Pro454Leu), located within the ANK repeats of the protein which suggest possible alteration of the BARD1 structure and/or interactions with other proteins. The information regarding the patient family was limited and it was unclear whether additional breast and/or ovarian cases were present in other family members (Fig. 1A). The germline mutation was found heterozygous in the tested tumor sample. The c.1361C >T was not detected in the control groups.

The second identified genetic variant was a non-sense mutation in exon 8 (c.1690C $>$ T, p.Gln564Ter) previously reported by us (27). This mutation is located between the ANK repeats and the BRCT domains. The alteration was found in patient \#53 diagnosed with serous ovarian cancer at the age of 65 . The patients' family showed a strong aggregation of the disease (Fig. 1B). The sisters of the proband were affected with breast cancer and lymphoma. In addition, three nieces were diagnosed with ovarian cancer at the age of 43 and a breast cancer at the age of $\sim 50$. This variant was not found in the studied control groups.

The third, possibly deleterious alteration, located in exon 10 (c.1972C $>$ T) was identified in patient \#150 affected with ovarian cancer at the age of $\sim 50$. The proband's paternal aunt and grandmother were diagnosed with hepatic metastases of unknown primary site (Fig. 1C). The substitution c.1972C $>$ T results in an amino acid change at position 658 (p.Arg658Cys), which is located between the two BRCT domains. This genetic variant was also detected in both control groups (unselected control group: $n=3 / 1,000 ; 0.3 \%$ and healthy individuals: 
A

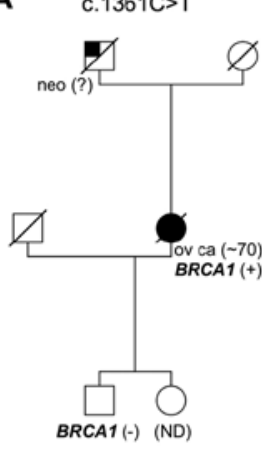

B

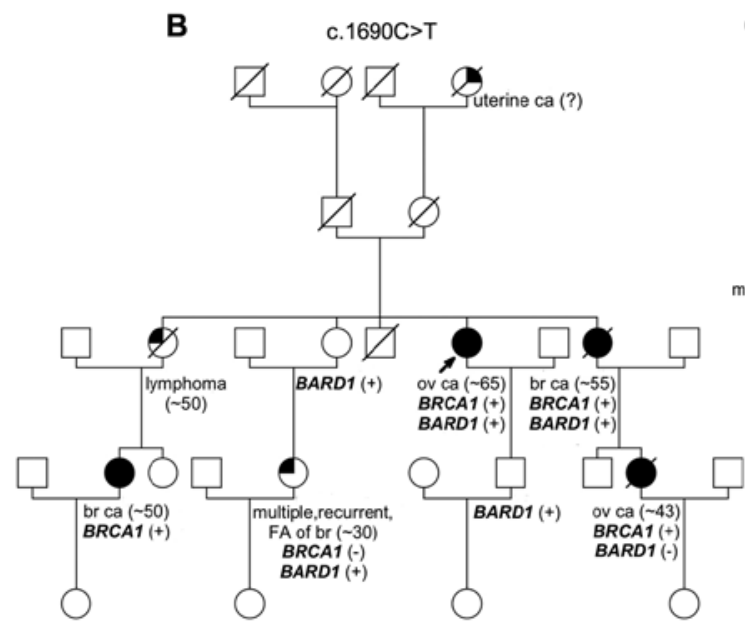

C

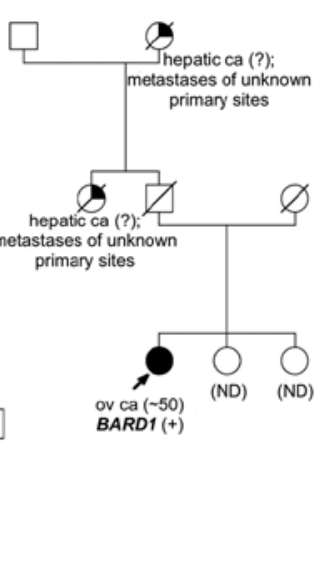

D

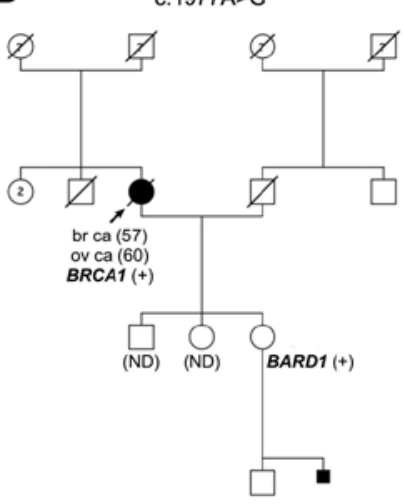

Figure 1. Co-segregation analysis. (A) Pedigree of family \#109 carrying mutation c.1361C $>\mathrm{T}$; (B) pedigree of family \#53 carrying mutation c.1690C $>\mathrm{T}$ (BARD1) and c.5266dupC (BRCA1); (C) pedigree of family \#150 carrying mutation c.1972C $>\mathrm{T}$; (D) pedigree of family \#4321 carrying mutation c.1977A $>\mathrm{G}$. ( ) proband; ( 70) age at diagnosis; (/) dead; (-) wild-type individuals; (+) individuals carrying mutation; (ND), not done. BARD1, BRCA1-associated RING domain 1.

$\mathrm{n}=2 / 200 ; 1 \%$ ) suggesting its limited significance. Analysis of the tumor sample revealed the heterozygous status of this substitution.

Finally, we identified a carrier (\#4321) of a previously described c.1977A $>$ G mutation in exon 10 (27). The patient was diagnosed with both breast and ovarian cancer at the age of 57 and 60, respectively. There was no information on other cancer cases within the proband's family. Although co-segregation analysis revealed that one of the proband's daughters was a carrier of this alteration (Fig. 1D). Tumor tissue was not available for the study. c.1977A $>$ G variant was also detected among control samples (unselected control group: $n=1 / 1,000$; $0.1 \%$ and healthy individuals: $n=2 / 200 ; 1 \%$ ).

Analysis of amplicons spanning the flanking intronic sequence of exons 5, 8 and 10 lead to identification of two frequent intronic variants c.1315-19A $>$ G (rs6704780) and c. $2001+66 \mathrm{~A}>\mathrm{G}$ (rs75237746), which are well-known polymorphisms (18). These were present in a studied group of patients with a frequency of 49 and $2.6 \%$, respectively. Because of the high frequency, and therefore presumably neutral character of these SNPs, we did not investigate their frequency in control groups.

Identification of a BARDI/ BRCA1 double mutation carrier. Interestingly, mutational analysis of the $B R C A l$ gene in patient \#53, positive for BARD1 alteration (c.1690C $>\mathrm{T}$ ), revealed the presence of a deleterious mutation c.5266dupC in exon 20. Further segregation analysis showed that both $B R C A 1$ and $B A R D 1$ mutations were present in other family members (Fig. 1B). Investigation of the mutation status in tumor tissue of patient \#53 reveled a heterozygotic character of both alterations.

Cancer-associated alterations of the BARDI gene affect splicing. In order to evaluate the possible effect of the identified $B A R D 1$ sequence alterations on protein function and splicing, in silico analysis was performed. The synonymous substitution c.1977A > G, previously reported to affect splicing (27), was used as indicator of accuracy in predicting potential splicing disruption. Although the employed software packages individually generated inconsistent results, the combined analyses indicated a possible influence of the tested mutations on the splicing process (Table III).

In order to confirm the in silico results, RT-PCR using RNA isolated from patients' peripheral blood cells was applied. In one case, due to the death of the patient with BARDI c.1361C $>\mathrm{T}$ substitution, RNA was extracted from the normal tissue macrodissected from the resected tumor sample. RT-PCR was performed with primers located within exons 4 and 6 . Agarose gel electrophoresis showed two prominent bands. The upper band had the expected wild-type size (218 bp) and the lower band of 137 bp corresponded to a fragment lacking exon 5 . Sequencing of the shorter band confirmed exon 5 skipping, resulting in in-frame deletion from c.1315 to c.1395 [r. $(=$, 1315_1395del); p.Gly439_Leu465del] (Fig. 2A-D). On the protein level, this deletion results in disruption of the 1st and 2nd ANK repeat.

Similarly, the c.1690C $>$ T mutation in exon 8 was examined. The RT-PCR experiment was performed using forward and reverse primers in exons 7 and 9, respectively. Once again agarose gel electrophoresis exhibited two bands: One band corresponding to the wild-type fragment (264 bp) and a lower band. Sequencing of the smaller band confirmed the presence of frame-shift deletion of exon 8 [r.(=,1678_1810del)], resulting in formation of premature stop codon at position p.Met560 (Fig. 2E-H).

Finally, c.1972C $>$ T substitution located in exon 10 was analyzed. RNA was extracted and RT-PCR using previously described primers was applied (27). Alteration c.1972C $>\mathrm{T}$ does not affect the splicing process.

Ovarian cancer-associated BARDl alterations might be cancer-specific. Ultimately, we analyzed 120 samples of patients with CML to assess the frequency of the newly identified BARD1 isoforms (lacking exon 5 and 8, respectively) in other, hormone-independent types of cancer. None of the 
analyzed sample showed the presence of $B A R D 1$ alterations resulting in formation of the isoforms lacking exons 5 or 8 (data not shown).

\section{Discussion}

All initial BARDl studies described a limited number of sequence variants, including several missense mutations and one in-frame deletion of $21 \mathrm{bp}$ with unknown consequence for the protein function. However, more recent studies reported several truncating mutations, which were segregating with the disease. Interestingly, $B A R D 1$ germline variants were identified not only in patients with breast and ovarian cancer $(12,24,27-29,31)$, but also among individuals with familial neuroblastoma (33).

In the present study, in a cohort of 255 unselected ovarian cancer cases, one novel and three previously reported genomic $B A R D 1$ alterations in exons 5, 8 and 10 (c.1361C $>\mathrm{T}$; c.1690C $>\mathrm{T}$, c.1972C $>$ T, c.1977A $>$ G) were identified. All four genetic variants were absent or infrequent in the control group (0.1-0.3\%), indicating their pathogenic potential.

c. $1361 \mathrm{C}>\mathrm{T}$ mutation disrupts the binding motif for splicing factor SC35 and results in an in-frame deletion of exon 5 and disruption of two presumably important ANK repeats. Based on previously published data, we assume that lack of 27 amino acids at positions p.Gly439_Leu465 may diminish the ability of BARD1 to induce apoptosis $(35,36)$. BARD1 mRNAs lacking exon 5 could be a full length (FL) BARD1 or mRNA isoforms lacking also other exons, namely BARD1 $\beta$, BARD1 $\alpha$, BARD1 $\kappa$, BARD1 $\phi$, BARD1 $\gamma$ (Fig. 3B), which have been described before for breast, ovarian, lung, colon cancer and neuroblastoma (37-40).

c. $1361 \mathrm{C}>\mathrm{T}$ is the second $B A R D 1$ mutation resulting in exon 5 skipping. In a previous study, we identified an intronic variant located in the donor site of intron 4 (c.1315-2A $>\mathrm{G})$ that also resulted in in-frame deletion of exon 5 (27). Exon 5 deletion was first observed in the ovarian cancer cell line NuTu-19 (41), derived from spontaneous mutation of rat ovarian cancer cells that recapitulates human ovarian cancer when injected intraperitoneally into mice. This cell line expressed no FL BARD1, but BARD1 $\beta$ which had an additional deletion of exon 5 (41). The NuTu-19 cells were resistant to apoptosis induction, but became sensitive when expressing exogenous FL BARD1 suggesting that loss of exon 5 leads to isoforms that have lost tumor-suppressor functions affecting the apoptosis pathway (41). BARD1 $\beta$ with an additional exon 5 deletion was also observed in mouse spermatogenesis (42). However, impact of exon 5 deletion on the function of FL BARD1 or BARD1 $\beta$ has not been determined.

The second identified alteration, c.1690C $>$ T, was located in exon 8. In silico analysis showed that this alteration significantly changed the binding motif for splicing factors. Splicing alteration was confirmed by RT-PCR [r.(=,1678_1810del), p.Met560*]. Translation of the c.1690C $>$ T mutation results in a truncated protein lacking the BRCT domains, which play an integral role in the DNA damage response (43). BRCA1 mutations located in BRCT domains are correlated with an increased risk for both breast and ovarian cancer $(44,45)$. It was demonstrated that BRCA1 truncated only by 10 amino acids is less stable, does not accumulate in the nucleus and 


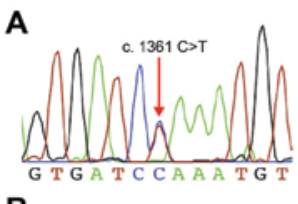

B

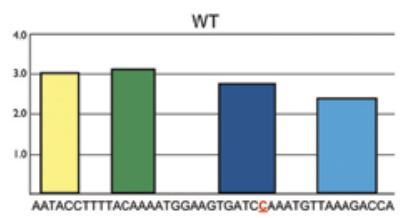

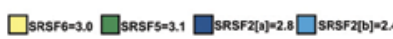
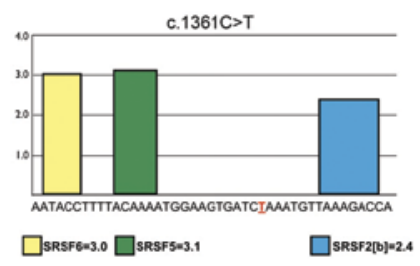

E

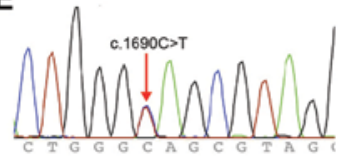

$\mathbf{F}$

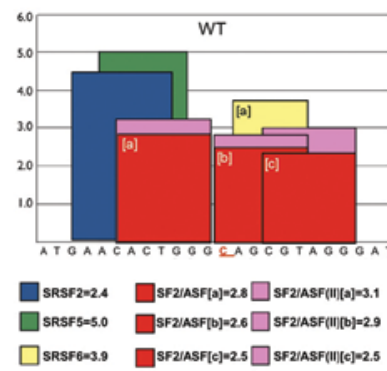

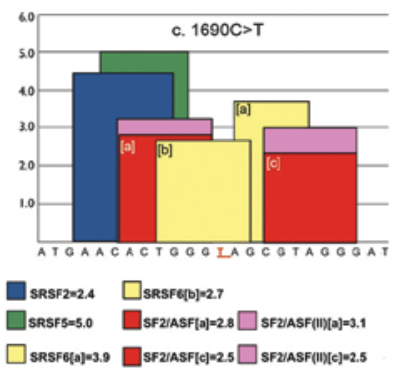

G

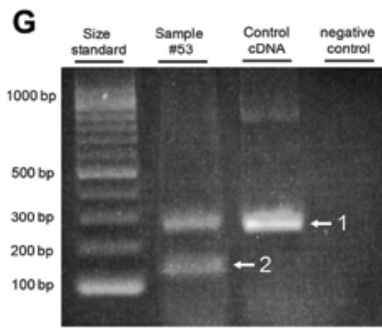

H

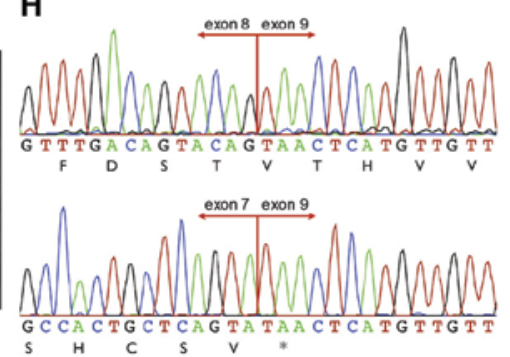

Figure 2. (A-D) Analysis of variant c.1361C $>$ T. (A) Sequence analysis of exon 5 of the BARD1 gene. The mutation is marked with an arrow. (B) In silico tools analysis shows left panel with original ESE motifs located within exon 5 and right panel with ESE motifs status in sequence that harbors the mutation. (C) mRNA expression analysis: Agarose gel electrophoresis of PCR spanning exon 5 revealed two bands: upper band (1) the expected wild-type allele (218 bp) and lower band (2) of 137 bp corresponding to deletion of exon 5. (D) Sequence of the wild-type band (top panel) and the bottom panel exhibit an in-frame deletion of exon 5 of BARD1 gene. (E-H) Analysis of mutation c.1690C $>\mathrm{T}$ in BARD1. (E) Sequencing results demonstrating alterations located in exon 8 of $B A R D 1$ gene (arrows). (F) In silico tool analysis shows original ESE motifs located within exon 8 of wild-type BARD1 and right panel with ESE motifs status after in BARD1 sequence with c.1690C $>$ T mutation. (G) Agarose gel electrophoresis revealed two bands: Upper band (1) of the expected wild-type allele (264 bp) and lower band (2) with a size of $131 \mathrm{bp}$. (H) cDNA sequence analysis confirmed sequence of the wild-type BARD1 (top panel) and deletion of exon 8 of BARD1 gene (bottom panel). BARD1, BRCA1-associated RING domain 1.

fails to colocalize with BARD1 and BRIP1 (44). It is therefore likely that lack of BARD1 BRCT domains have a similar impact on protein function.

In addition, this mutation could not only produce a truncated product of FL BARD1 mRNA, but also truncated proteins from BARD1 isoform mRNAs (Fig. 3C). Previously we reported the $B A R D 1 \mathrm{c} .1690 \mathrm{C}>\mathrm{T}$ alteration as a non-sense mutation (27), but additional studies showed its impact on splicing alteration.

Moreover, the carrier of c. $1690 \mathrm{C}>\mathrm{T}$ mutation in $B A R D I$ was also diagnosed with mutation c.5266dupC in the BRCAI gene. The duplication of the cytosine at position c.5266 is the second most frequent BRCAl mutation all over the world and the most common in Poland $(10,11,18)$. The c.1690C $>\mathrm{T}$ mutation in $B A R D 1$ was previously described in a family with an aggregation of breast, colon, and uterine cancer and was further identified in four different families with aggregation of breast and ovarian cancer (27, and Ratajska unpublished data). Co-existence of $B A R D 1$ and $B R C A 1$ could have either an aggravating or a mitigating affect. However, co-segregation of both mutations may indicate the latter. Another case of co-occurrence of germline BARDI (p.Gln715Ter) and BRCAI (c.3600del11) mutations was described in a patient with serous carcinoma (28). Moreover, co-occurrence of a BARDI (p.Cys557Ser) germline alteration with a BRCA2 (c.771_775del) truncating mutation was reported as a risk amplifying factor to carriers of both mutations (46). As BRCA1, BRCA2 and BARD1 act together in several tumor suppressor pathways, it is likely that double mutations increase the risk of cancer.

Within this study group, we identified a carrier of recurrent BARD1 missense mutation (c.1972C $>$ T; p.Arg658Cys) located in exon 10. Several studies have classified c.1972C $>$ T substitution as possibly deleterious (29) or with unknown significance $(25,30,47)$. Rudd et al suggested its correlation with a risk of lung cancer with an odds ratio 1.55 (47). In our study, in silico analysis performed by using Mutation Tester, PolyPhen, and SIFT indicated its potentially damaging character. However, RT-PCR showed that this variant does not alter the splicing of $B A R D 1$ gene.

Finally, we described another case of synonymous change (c.1977A $>$ G) that results in aberrant splicing, leading to a transcript lacking exons 2-9. This mRNA is identical to BARD1 $\eta$ (Fig. 3A), which can either be translated from the first methionine and end with a premature stop codon in exon 10 (p.Cys53_Trp635delinsfs"12), or translation could start with a first methionine in an alternative open reading frame (ORF) $(39,48)$. This c.1977A $>$ G alteration was previously identified and characterized in a patient with clear cell ovarian cancer with familial aggregation of the disease (27). Additionally, BARD1 $\eta$ isoform was found by Li et al in human 
A

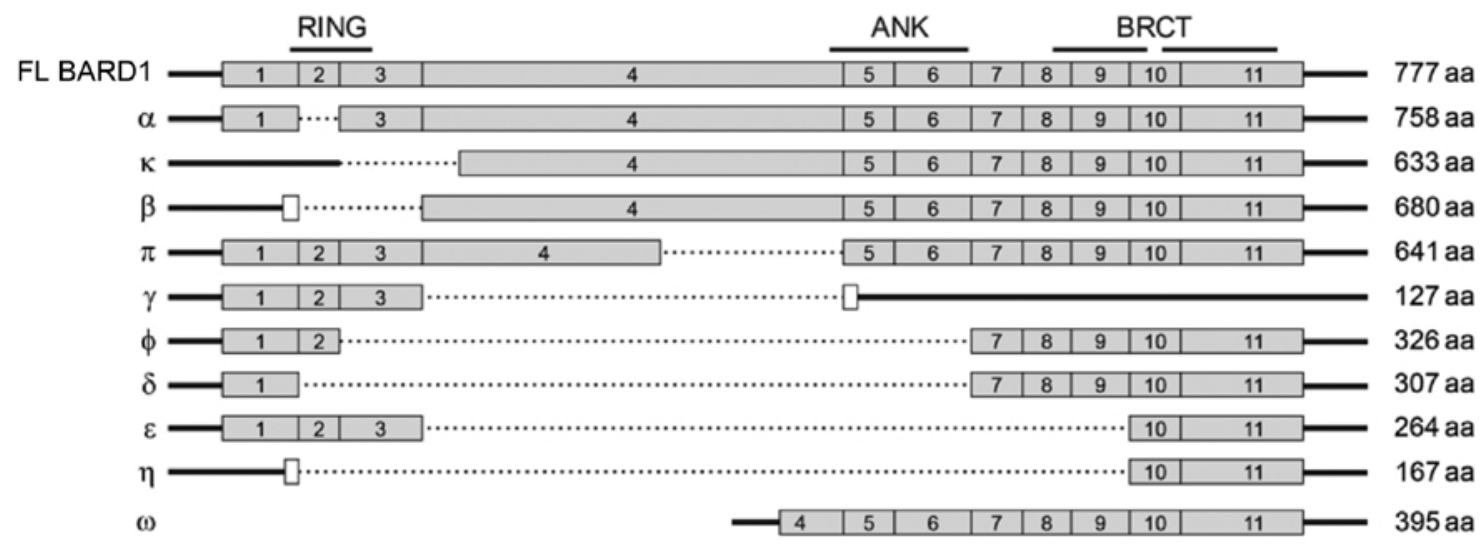

B

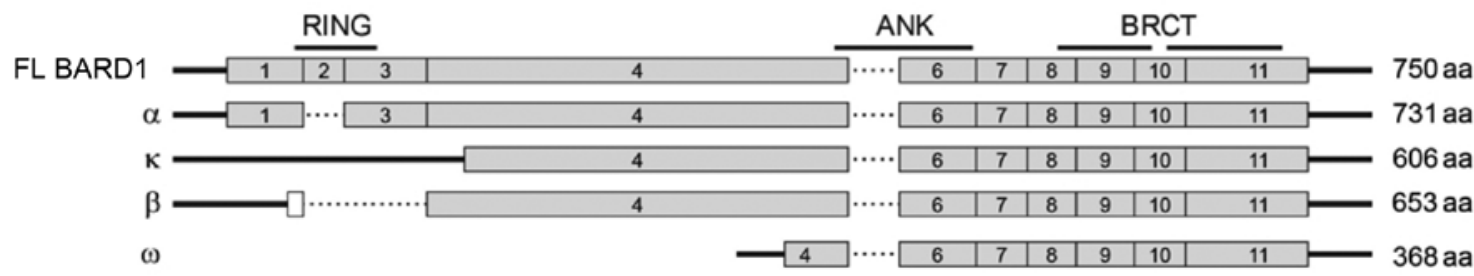

C

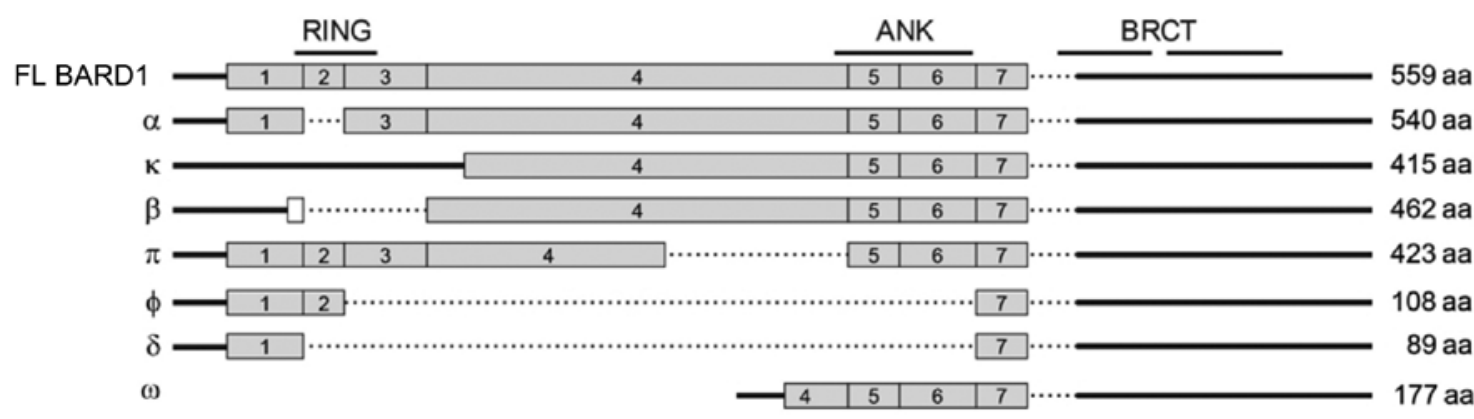

Figure 3. The schematic structure of protein coding FL BARD1 mRNA and splice isoforms is presented (A). Thick line, non-coding sequences; dashed bar, exon skipping; gray bars, protein coding sequence corresponding the main BARD1 reading frame. White bars, alternative, in-frame ORFs. The positions of RING domain, ANK repeats and BRCT domains are shown on the top. The expected length of the polypeptides encoded by the isoforms is shown on the right. (B) The structure of the BARD1 splice isoforms with the exon 5 skipping. (C) The structure of the BARD1 splice isoforms with exon 8 skipping. BARD1, BRCA1-associated RING domain 1; FL, full length; ORF, open reading frame; ANK, ankyrin.

cytotrophoblast invasion and in gynecological cancers, and authors showed the presence of a $21-\mathrm{kDa}$ protein, consistence with the predicted molecular weight of BARD1 $\eta(39,48)$.

Importantly, our results underscore the necessity of multilevel $B A R D 1$ mutation screening, as the molecular analysis limited to DNA may result in high-level misclassification of the detected genetic variants. This phenomenon was widely studied in $N F 1$ and $A T M$, where authors demonstrated that $\sim 13 \%$ of patients may be incorrectly diagnosed (49-51).

Several studies demonstrated that BARD1 isoforms are widely expressed in different types of cancer and that spliced isoforms are often more abundant than FL BARD1 (37-40). Moreover, RNA interference experiments suggested that BARD1 splice variants have functional roles and are the driving force of tumorigenesis $(37,39,40,52-54)$. It was shown that the expression of alternatively spliced BARD1 isoforms was associated with poor outcome and short survival of breast and lung cancer patients. The link between sequence alterations and alternative splicing causing tumorigenesis was convincingly demonstrated for neuroblastoma (40). SNPs that are significantly associated with aggressive neuroblastoma were identified in intronic sequences of $B A R D 1$. Increased expression of BARD1 $\beta$ was linked to the disease-associated SNP and to functions in malignant transformation (40).

Thus, we suggest that germline $B A R D 1$ mutations are responsible for a portion of hereditary ovarian cancers and $B A R D 1$ should be included in gene panels that are used for molecular diagnosis of breast and ovarian patients. The actual pathogenic role of $B A R D 1$ sequence variants is rather due to activation of alternative splicing and enhanced expression 
of certain isoforms than mutations per se. Even apparently harmless variants may lead to incorrect splicing process and expression of oncogenic dominant negative forms of BARD1.

\section{Acknowledgements}

The authors wish to thank all the patients and their families who participated in this study for their invaluable contribution. This study was supported by the Polish National Science Centre projects: N407 627740, 2011/02/A/NZ2/00017, 2011/01/B/NZ5/02773.

\section{References}

1. Jemal A, Murray T, Ward E, Samuels A, Tiwari RC, Ghafoor A Feuer EJ and Thun MJ: Cancer statistics, 2005. CA Cancer J Clin 55: 10-30, 2005.

2. Urban $\mathrm{N}$ and Drescher C: Potential and limitations in early diagnosis of ovarian cancer. Adv Exp Med Biol 622: 3-14, 2008.

3. Ruddon RW: Cancer Biology. Oxford University Press, USA, 2007.

4. Bast RC Jr, Hennessy B and Mills GB: The biology of ovarian cancer: New opportunities for translation. Nat Rev Cancer 9: 415-428, 2009.

5. Berchuck A, Heron KA, Carney ME, Lancaster JM, Fraser EG, Vinson VL, Deffenbaugh AM, Miron A, Marks JR, Futreal PA, et al: Frequency of germline and somatic BRCA1 mutations in ovarian cancer. Clin Cancer Res 4: 2433-2437, 1998.

6. Malander S, Ridderheim M, Måsbäck A, Loman N, Kristoffersson U, Olsson H, Nilbert $\mathrm{M}$ and Borg A: One in 10 ovarian cancer patients carry germ line BRCA1 or BRCA2 mutations: Results of a prospective study in Southern Sweden. Eur J Cancer 40: 422-428, 2004.

7. Risch HA, McLaughlin JR, Cole DE, Rosen B, Bradley L, Kwan E, Jack E, Vesprini DJ, Kuperstein G, Abrahamson JL, et al: Prevalence and penetrance of germline BRCA1 and BRCA2 mutations in a population series of 649 women with ovarian cancer. Am J Hum Genet 68: 700-710, 2001.

8. Hirsh-Yechezkel G, Chetrit A, Lubin F, Friedman E, Peretz T, Gershoni R, Rizel S, Struewing JP and Modan B: Population attributes affecting the prevalence of BRCA mutation carriers in epithelial ovarian cancer cases in Israel. Gynecol Oncol 89: 494-498, 2003.

9. Menkiszak J, Gronwald J, Górski B, Jakubowska A, Huzarski T, Byrski T, Foszczyńska-Kłoda M, Haus O, Janiszewska H, Perkowska M, et al: Hereditary ovarian cancer in Poland. Int J Cancer 106: 942-945, 2003.

10. Brozek I, Ochman K, Debniak J, Morzuch L, Ratajska M, Stepnowska M, Stukan M, Emerich J and Limon J: High frequency of BRCA $1 / 2$ germline mutations in consecutive ovarian cancer patients in Poland. Gynecol Oncol 108: 433-437, 2008.

11. Ratajska M, Krygier M, Stukan M, Kuźniacka A, Koczkowska M, Dudziak M, Śniadecki M, Dębniak J, Wydra D, Brozek I, et al: Mutational analysis of BRCA1/2 in a group of 134 consecutive ovarian cancer patients. Novel and recurrent BRCA1/2 alterations detected by next generation sequencing. J Appl Genet 56: 193-198, 2015.

12. Walsh T, Casadei S, Lee MK, Pennil CC, Nord AS, Thornton AM, Roeb W, Agnew KJ, Stray SM, Wickramanayake A, et al: Mutations in 12 genes for inherited ovarian, fallopian tube, and peritoneal carcinoma identified by massively parallel sequencing. Proc Natl Acad Sci USA 108: 18032-18037, 2011.

13. Apostolou P and Fostira F: Hereditary breast cancer: The era of new susceptibility genes. Biomed Res Int 2013: 747318, 2013.

14. Walsh T and King MC: Ten genes for inherited breast cancer. Cancer Cell 11: 103-105, 2007.

15. Wu LC, Wang ZW, Tsan JT, Spillman MA, Phung A, Xu XL, Yang MC, Hwang LY, Bowcock AM and Baer R: Identification of a RING protein that can interact in vivo with the BRCA1 gene product. Nat Genet 14: 430-440, 1996.

16. Irminger-Finger I and Jefford CE: Is there more to BARD1 than BRCA1? Nat Rev Cancer 6: 382-391, 2006.
17. Irminger-Finger I, Soriano JV, Vaudan G, Montesano R and Sappino AP: In vitro repression of Brca1-associated RING domain gene, Bard1, induces phenotypic changes in mammary epithelial cells. J Cell Biol 143: 1329-1339, 1998.

18. Williams RS, Bernstein N, Lee MS, Rakovszky ML, Cui D, Green R, Weinfeld M and Glover JN: Structural basis for phosphorylation-dependent signaling in the DNA-damage response. Biochem Cell Biol 83: 721-727, 2005.

19. Baer R and Ludwig T: BRCA1/BARD1 heterodimer, a tumor suppressor complex with ubiquitin E3 ligase activity. Curr Opin Genet Dev 12: 86-91, 2002.

20. Sedgwick SG and Smerdon SJ: The ankyrin repeat: A diversity of interactions on a common structural framework. Trends Biochem Sci 24: 311-316, 1999.

21. Li J, Mahajan A and Tsai MD: Ankyrin repeat: A unique motif mediating protein-protein interactions. Biochemistry 45: 15168-15178, 2006.

22. Irminger-Finger I, Leung WC, Li J, Dubois-Dauphin M, Harb J, Feki A, Jefford CE, Soriano JV, Jaconi M, Montesano R, et al: Identification of BARD1 as mediator between proapoptotic stress and p53-dependent apoptosis. Mol Cell 8: 1255-1266, 2001.

23. McCarthy EE, Celebi JT, Baer R and Ludwig T: Loss of Bard1, the heterodimeric partner of the Brcal tumor suppressor, results in early embryonic lethality and chromosomal instability. Mol Cell Biol 23: 5056-5063, 2003.

24. Sabatier R, Adélaïde J, Finetti P, Ferrari A, Huiart L, Sobol H, Chaffanet M, Birnbaum D and Bertucci F: BARD1 homozygous deletion, a possible alternative to BRCA1 mutation in basal breast cancer. Genes Chromosomes Cancer 49: 1143-1151, 2010.

25. Thai TH, Du F, Tsan JT, Jin Y, Phung A, Spillman MA, Massa HF, Muller CY, Ashfaq R, Mathis JM, et al: Mutations in the BRCA1-associated RING domain (BARD1) gene in primary breast, ovarian and uterine cancers. Hum Mol Genet 7: 195-202, 1998.

26. Kleiman FE and Manley JL: The BARD1-CstF-50 interaction links mRNA 3' end formation to DNA damage and tumor suppression. Cell 104: 743-753, 2001.

27. Ratajska M, Antoszewska E, Piskorz A, Brozek I, Borg Å, Kusmierek H, Biernat $\mathrm{W}$ and Limon J: Cancer predisposing BARD1 mutations in breast-ovarian cancer families. Breast Cancer Res Treat 131: 89-97, 2012.

28. Pennington KP, Walsh T, Harrell MI, Lee MK, Pennil CC, Rendi MH, Thornton A, Norquist BM, Casadei S, Nord AS, et al: Germline and somatic mutations in homologous recombination genes predict platinum response and survival in ovarian, fallopian tube, and peritoneal carcinomas. Clin Cancer Res 20: 764-775, 2014.

29. De Brakeleer S, De Grève J, Loris R, Janin N, Lissens W, Sermijn E and Teugels E: Cancer predisposing missense and protein truncating BARD1 mutations in non-BRCA1 or BRCA2 breast cancer families. Hum Mutat 31: E1175-E1185, 2010.

30. Karppinen SM, Heikkinen K, Rapakko $\mathrm{K}$ and Winqvist R: Mutation screening of the BARD1 gene: Evidence for involvement of the Cys557Ser allele in hereditary susceptibility to breast cancer. J Med Genet 41: e114, 2004.

31. Castéra L, Krieger S, Rousselin A, Legros A, Baumann JJ, Bruet O, Brault B, Fouillet R, Goardon N, Letac O, et al: Next-generation sequencing for the diagnosis of hereditary breast and ovarian cancer using genomic capture targeting multiple candidate genes. Eur J Hum Genet 22: 1305-1313, 2014

32. Narayan G, Pulido HA, Koul S, Lu XY, Harris CP, Yeh YA, Vargas H, Posso H, Terry MB, Gissmann L, et al: Genetic analysis identifies putative tumor suppressor sites at 2q35-q36.1 and 2q36.3-q37.1 involved in cervical cancer progression. Oncogene 22: 3489-3499, 2003.

33. Pugh TJ, Morozova O, Attiyeh EF, Asgharzadeh S, Wei JS, Auclair D, Carter SL, Cibulskis K, Hanna M, Kiezun A, et al: The genetic landscape of high-risk neuroblastoma. Nat Genet 45: 279-284, 2013.

34. den Dunnen JT and Antonarakis SE: Nomenclature for the description of human sequence variations. Hum Genet 109: 121-124, 2001.

35. Jefford CE, Feki A, Harb J, Krause KH and Irminger-Finger I: Nuclear-cytoplasmic translocation of BARD1 is linked to its apoptotic activity. Oncogene 23: 3509-3520, 2004.

36. Fox D III, Le Trong I, Rajagopal P, Brzovic PS, Stenkamp RE and Klevit RE: Crystal structure of the BARD1 ankyrin repeat domain and its functional consequences. J Biol Chem 283: 21179-21186, 2008. 
37. Zhang YQ, Pilyugin M, Kuester D, Leoni VP, Li L, Casula G, Zorcolo L, Schneider-Stock R, Atzori L and Irminger-Finger I: Expression of oncogenic BARD1 isoforms affects colon cancer progression and correlates with clinical outcome. Br J Cancer 107: 675-683, 2012.

38. Zhang YQ, Bianco A, Malkinson AM, Leoni VP, Frau G, De Rosa N, André PA, Versace R, Boulvain M, Laurent GJ, et al: BARD1: An independent predictor of survival in non-small cell lung cancer. Int J Cancer 131: 83-94, 2012.

39. Li L, Ryser S, Dizin E, Pils D, Krainer M, Jefford CE, Bertoni F, Zeillinger R and Irminger-Finger I: Oncogenic BARD1 isoforms expressed in gynecological cancers. Cancer Res 67: 11876-11885, 2007.

40. Bosse KR, Diskin SJ, Cole KA, Wood AC, Schnepp RW, Norris G, Nguyen le B, Jagannathan J, Laquaglia M, Winter C, et al: Common variation at BARD1 results in the expression of an oncogenic isoform that influences neuroblastoma susceptibility and oncogenicity. Cancer Res 72: 2068-2078, 2012.

41. Feki A, Jefford CE, Berardi P, Wu JY, Cartier L, Krause KH and Irminger-Finger I: BARD1 induces apoptosis by catalysing phosphorylation of p53 by DNA-damage response kinase. Oncogene 24: 3726-3736, 2005.

42. Feki A, Jefford CE, Durand P, Harb J, Lucas H, Krause KH and Irminger-Finger I: BARD1 expression during spermatogenesis is associated with apoptosis and hormonally regulated. Biol Reprod 71: 1614-1624, 2004

43. Leung CC and Glover JN: BRCT domains: Easy as one, two, three. Cell Cycle 10: 2461-2470, 2011.

44. Nelson AC and Holt JT: Impact of RING and BRCT domain mutations on BRCA1 protein stability, localization and recruitment to DNA damage. Radiat Res 174: 1-13, 2010.

45. di Masi A, Gullotta F, Cappadonna V, Leboffe L and Ascenzi P: Cancer predisposing mutations in BRCT domains. IUBMB Life 63: 503-512, 2011.

46. Stacey SN, Sulem P, Johannsson OT, Helgason A, Gudmundsson J, Kostic JP, Kristjansson K, Jonsdottir T, Sigurdsson H, Hrafnkelsson J, et al: The BARD1 Cys557Ser variant and breast cancer risk in Iceland. PLoS Med 3: e217, 2006.
47. Rudd MF, Webb EL, Matakidou A, Sellick GS, Williams RD, Bridle H, Eisen T and Houlston RS; GELCAPS Consortium: Variants in the GH-IGF axis confer susceptibility to lung cancer. Genome Res 16: 693-701, 2006.

48. Li L, Cohen M, Wu J, Sow MH, Nikolic B, Bischof P and Irminger-Finger I: Identification of BARD1 splice-isoforms involved in human trophoblast invasion. Int $\mathrm{J}$ Biochem Cell Biol 39: 1659-1672, 2007

49. Ars E, Kruyer H, Gaona A, Serra E, Lazaro C and Estivill X Prenatal diagnosis of sporadic neurofibromatosis type 1 (NF1) by RNA and DNA analysis of a splicing mutation. Prenat Diagn 19: 739-742, 1999.

50. Baralle D and Baralle M: Splicing in action: Assessing disease causing sequence changes. J Med Genet 42: 737-748, 2005.

51. Teraoka SN, Telatar M, Becker-Catania S, Liang T, Onengüt S, Tolun A, Chessa L, Sanal O, Bernatowska E, Gatti RA, et al: Splicing defects in the ataxia-telangiectasia gene, ATM: Underlying mutations and consequences. Am J Hum Genet 64 : 1617-1631, 1999.

52. Ryser S, Dizin E, Jefford CE, Delaval B, Gagos S Christodoulidou A, Krause KH, Birnbaum D and Irminger-Finger I: Distinct roles of BARD1 isoforms in mitosis: Full-length BARD1 mediates Aurora B degradation, cancer-associated BARD1beta scaffolds Aurora B and BRCA2. Cancer Res 69: 1125-1134, 2009.

53. Woditschka S, Evans L, Duchnowska R, Reed LT, Palmieri D, Qian Y, Badve S, Sledge G Jr, Gril B, Aladjem MI, et al: DNA double-strand break repair genes and oxidative damage in brain metastasis of breast cancer. J Natl Cancer Inst 106: pii: dju145, 2014.

54. Chen J and Weiss WA: Alternative splicing in cancer: Implications for biology and therapy. Oncogene 34: 1-14, 2015. 